\title{
Suicidal ideation and the risk of suicide in patients with fibromyalgia: a comparison with non-pain controls and patients suffering from low-back pain
}

\author{
This article was published in the following Dove Press journal: \\ Neuropsychiatric Disease and Treatment \\ 16 April 2014 \\ Number of times this article has been viewed
}

Irene Jimenez-Rodríguez' Juan Miguel Garcia-Leiva' Beatriz M Jimenez-Rodriguez ${ }^{2}$ Emilia Condés-Moreno ${ }^{3}$ Fernando Rico-

Villademoros'

\section{Elena $\mathrm{P}$ Calandre}

'Instituto de Neurociencias, Universidad de Granada, Granada, Spain; ${ }^{2}$ Servicio de Neumología, Hospital Universitario Virgen de las Nieves, Granada, Spain; ${ }^{3}$ Departamento de Especialidades Biomédicas, Universidad Europea de Madrid, Villaviciosa de Odón, Spain

Correspondence: Elena P Calandre Instituto de Neurociencias, Universidad de Granada, Avenida de Madrid I I, Granada, Spain

Tel +3495824 629l

Fax +34958243537

Email calandre@gmail.com
Abstract: Fibromyalgia is associated with an increased rate of mortality from suicide. In fact, this disease is associated with several characteristics that are linked to an increased risk of suicidal behaviors, such as being female and experiencing chronic pain, psychological distress, and sleep disturbances. However, the literature concerning suicidal behaviors and their risk factors in fibromyalgia is sparse. The objectives of the present study were to evaluate the prevalence of suicidal ideation and the risk of suicide in a sample of patients with fibromyalgia compared with a sample of healthy subjects and a sample of patients with chronic low-back pain. We also aimed to evaluate the relevance of pain intensity, depression, and sleep quality as variables related to suicidal ideation and risks. Logistic regression was applied to estimate the likelihood of suicidal ideation and the risk of suicide adjusted by age and sex. We also used two logistic regression models using age, sex, pain severity score, depression severity, sleep quality, and disease state as independent variables and using the control group as a reference. Forty-four patients with fibromyalgia, 32 patients with low-back pain, and 50 controls were included. Suicidal ideation, measured with item 9 of the Beck Depression Inventory, was almost absent among the controls and was low among patients with low-back pain; however, suicidal ideation was prominent among patients with fibromyalgia $(P<0.0001)$. The risk of suicide, measured with the Plutchik Suicide Risk Scale, was also higher among patients with fibromyalgia than in patients with low-back pain or in controls $(P<0.0001)$. The likelihood for suicidal ideation and the risk of suicide were higher among patients with fibromyalgia (odds ratios of 26.9 and 48.0 , respectively) than in patients with low-back pain (odds ratios 4.6 and 4.7, respectively). Depression was the only factor associated with suicidal ideation or the risk of suicide.

Keywords: chronic low-back pain, suicidal risk, depression

\section{Introduction}

Two large population-based studies, one from Denmark and one from the United States, have shown that fibromyalgia is associated with an increased frequency of death from suicide. ${ }^{1-2}$ A later study, performed in Spain, also showed a high frequency of previous suicide attempts among patients with fibromyalgia. ${ }^{3}$

Pain is the cardinal symptom of fibromyalgia, and chronic pain has been related to an increased probability of suicidal behaviors (ie, suicidal ideation, suicide attempts, and completed suicide). ${ }^{4,5}$ It is also important to remember that most patients with fibromyalgia also suffer from sleep disturbances ${ }^{6}$ and symptoms of psychological distress, such as anxiety and depression, ${ }^{7}$ and that both depression and sleep alterations 
are factors that are strongly associated with the likelihood of suicide. ${ }^{8,9}$ In addition, female sex is also a predisposing factor to suicide, ${ }^{8}$ and fibromyalgia is a pathology that is more common in women than in men. ${ }^{10}$ Thus, many patients with fibromyalgia may present several risk factors for suicide.

Although the literature concerning chronic pain and suicidality is ample, the prevalence of suicidal behaviors among patients with fibromyalgia and the specific relevance of factors predisposing patients to these behaviors have scarcely been investigated, which is in contrast with other types of chronic pain, such as headaches, migraines, arthritis, back pain, bladder pain, or irritable bowel syndrome. Among four recent population-based studies that examined the association between chronic pain and suicidal behaviors, ${ }^{11-14}$ only two included patients with fibromyalgia. ${ }^{11,14}$

The main objective of the present study was to evaluate suicidal ideation and the risk of suicide in a sample of patients with fibromyalgia and to compare these patients with a sample of control subjects from the general population as well as with a sample of patients with low-back pain, which represents a condition that involves chronic pain that is frequently found in clinical practice and that has been associated both with depression ${ }^{15,16}$ and with sleep disturbances. ${ }^{17,18}$ A secondary objective was to compare depression, sleep quality, and pain intensity in the three samples as variables that may be relevant to suicidal behaviors.

\section{Patients and methods Subjects}

The inclusion criteria were: age $\geq 18$ years old, an understanding of the requirements of the study, and providing written informed consent. Patients with fibromyalgia were diagnosed according to the American College of Rheumatology 1990 criteria. ${ }^{19}$ Patients with low-back pain had to have experienced constant or intermittent nonspecific low-back pain for at least the last 3 months. Exclusion criteria for patients included any mental disorder other than the symptoms of depression. Patients were recruited in a primary care center; those patients who had been diagnosed with fibromyalgia or low-back pain were invited to participate in the study. They were informed that the objective of the study was to examine the relationship between suicidal ideation and chronic pain. Those who accepted were examined to evaluate whether they fulfilled the inclusion and exclusion criteria and were then given the questionnaire. Controls were recruited from the friends and colleagues of the investigators; they were included if they did not suffer from a mental disorder or from chronic pain. To preserve the anonymity of the answers, the subjects were instructed to send the completed questionnaires by mail or to deliver them in a sealed envelope.

The recruited participants were given a case report form that included questions concerning sociodemographic data (age, sex, education level, and marital and employment status) and the various outcome measures described below.

The study protocol was approved by the Ethics Committee of the Hospital Universitario Virgen de las Nieves of Granada (Spain).

\section{Methods}

Suicidal ideation was evaluated according to the answer given to question 9 of the Beck Depression Inventory (BDI). The BDI is a widely used self-assessment on a 21 -item scale that has a maximum total score of 63; higher scores indicate an increased severity of depression. Item 9 can be scored as: 0 ("I don't have any thoughts of harming myself"), which is considered to be the absence of suicidal ideation; 1 ("I have thoughts of harming myself but I would not carry them out"), which is considered to be passive suicidal ideation; 2 ("I would like to kill myself"); or 3 ("I would kill myself if I had the chance"), which is considered to be active suicidal ideation. Depression severity was measured by the BDI total score after subtracting the value for item 9 to measure the severity of depression independent of suicidal ideation; this approach avoids the artificial inflation of depression scores by this item and has been used in other studies that have evaluated suicidal ideation in patients with chronic pain. ${ }^{20-22}$ Clinically relevant depression was considered to be present when the total BDI scores were $\geq 18$ points. We used the Spanish validated version of the BDI that was assessed in a sample of 445 Spaniards, which showed good internal consistency (Cronbach's alpha: 0.83). ${ }^{23}$

The risk of suicide was measured with the Plutchik Suicide Risk Scale. This scale is a 15 -item self-reported measure designed to describe the degree to which an individual reveals characteristics that are similar to those consistent with suicidal behavior; each question is scored as one point, to a maximum of 15 . We used the Spanish validated version that was assessed in 672 Spaniards: $35 \%$ of the participants had a history of a previous suicide attempt, $17 \%$ had been diagnosed with antisocial or borderline personality disorder, and $48 \%$ came from the general population. This version showed an internal consistency of 0.9 (Cronbach's alpha) and a test-retest reliability of 0.89 (Pearson's correlation); the cutoff point that indicated a substantial suicide risk was established as 6 points. ${ }^{24}$ 
Sleep was evaluated with the Pittsburgh Sleep Quality Index (PSQI), which is a self-reported scale that has a maximum value of 21 , with high values indicating worse sleep quality; the cutoff point for poor sleep quality is 5 . We used the Spanish validated version, which was assessed in two samples: one of 181 students and another of 393 patients. Its internal consistency was 0.81 (Cronbach's alpha); it showed a sensitivity of $88.63 \%$ and a specificity of $74.99 \%$, with a Kappa coefficient of $0.61 .{ }^{25}$

Pain intensity was measured by the Brief Pain Inventory (BPI), which is a self-reported scale that measures both pain intensity and pain interference with daily activities on a visual analog scale ranging from 0 to 10 ; high values indicate higher levels of pain severity and interference. We used the Spanish validated version, which was assessed in 126 patients suffering from pain related to cancer; it showed an internal consistency of 0.87 for pain intensity and of 0.98 for pain interference (Cronbach's alpha). The test-retest reliability was 0.53 and 0.77 , respectively (Spearman's correlation). ${ }^{26}$

General health status was measured by the Short-Form Health Survey SF-12; this scale provides a physical component summary and a mental component summary, with higher scores indicating a better health status. We used the Spanish validated version, which was assessed in two wide samples of Spaniards ( $\mathrm{N}=1,579$ and $\mathrm{N}=1,798$, respectively); it showed an internal consistency of 0.94 for the physical component summary and of 0.9 for the mental component summary (Cronbach's alpha). ${ }^{27}$

\section{Data analysis}

Raw data from patients with fibromyalgia, patients with low-back pain, and controls were compared with the
Kruskal-Wallis test for a global comparison, with the Dunn's test for multiple comparisons between groups for parametric data, and with a $\chi^{2}$ test for categorical data. We estimated the likelihood of suicidal ideation or the risk of suicide, adjusting for age and sex using logistic regression models. Similarly, to evaluate the predictive factors for the presence of suicidal ideation and the risk of suicide, we also used two logistic regression models, including age, sex, BPI severity score, BDI total score, PSQI total score, and disease state as independent variables, using the control group as a reference. Data were analyzed with SPSS Statistics (IBM Corporation, Armonk, NY, USA) software, version 20.

\section{Results}

A total of 126 subjects, 44 patients with fibromyalgia, 50 controls, and 32 patients with low-back pain, were included. All of the participants completed the BDI, the Plutchik scale, the PSQI, and the BPI, but ten (7.9\%) had missing responses on the SF-12 questionnaire. Missing data were also found among the sociodemographic data shown in Table 1. Clinically relevant depression was found in two (4\%) controls, 13 (41\%) patients with low-back pain, and 40 (91\%) patients with fibromyalgia $\left(\chi^{2}: 72.03 ; P<0.0001\right)$. Poor sleep quality, indicated by PSQI scores above the cutoff point, was found in 22 (44\%) controls, 26 (81.3\%) low-back pain patients, and $38(86.4 \%)$ patients with fibromyalgia $\left(\chi^{2}: 22.73 ; P<0.0001\right)$.

Table 2 shows the evaluated pain, depression, sleep quality, and physical and mental health status in the three studied groups. The mean pain intensity was similar in fibromyalgia and in low-back pain patients, although pain interference with daily activities was higher among patients with fibromyalgia

Table I Sociodemographic data of the participants

\begin{tabular}{|c|c|c|c|c|c|}
\hline & $\mathbf{N}$ & $\begin{array}{l}\text { Control } \\
(\mathrm{N}=50)\end{array}$ & $\begin{array}{l}F M \\
(N=44)\end{array}$ & $\begin{array}{l}\text { LBP } \\
(\mathrm{N}=32)\end{array}$ & $P$-value \\
\hline Age (mean \pm standard deviation; years) & 115 & $50.5 \pm 7.5$ & $54.5 \pm 12.7$ & $50.1 \pm 8.2$ & 0.1844 \\
\hline Sex (female/male) & $95 / 31$ & $36 / 14$ & $4 I / 3$ & $18 / 14$ & 0.0009 \\
\hline Marital status & 94 & & & & \\
\hline Single/divorced/widowed & & 29 & 8 & 7 & 0.3773 \\
\hline Married/de facto & & 6 & 17 & 27 & \\
\hline Educational status & 105 & & & & \\
\hline No school/primary school & & 6 & 17 & 26 & $<0.0001$ \\
\hline Secondary school/university & & 33 & 8 & 15 & \\
\hline Employment status & 108 & & & & \\
\hline Work only at home & & 2 & 4 & 10 & $<0.0001$ \\
\hline Work outside home & & 37 & 12 & 4 & \\
\hline Sick leave & & 0 & 2 & 15 & \\
\hline Unemployed & & 0 & 4 & 5 & \\
\hline Retired & & 4 & 4 & 5 & \\
\hline
\end{tabular}

Abbreviations: FM, fibromyalgia; LBP, low-back pain. 
Table 2 Differences between groups in total depression and sleep quality scores, mean pain intensity and severity, and physical and mental health components

\begin{tabular}{lllll}
\hline & $\begin{array}{l}\text { Control vs } \\
\text { FM }\end{array}$ & $\begin{array}{l}\text { Control vs } \\
\text { LBP }\end{array}$ & $\begin{array}{l}\text { FM vs } \\
\text { LBP }\end{array}$ & $\begin{array}{l}\text { P-value (global } \\
\text { comparison) }\end{array}$ \\
\hline BPI intensity & $-67.41^{\#}$ & $-53.75^{\#}$ & $-13.65^{\text {ns }}$ & $<0.0001$ \\
BPI & $-67.07^{\#}$ & $-44.02^{\#}$ & $-23.04^{*}$ & $<0.0001$ \\
interference & & & & \\
BDI & $-65.91^{\#}$ & $-30.18^{\#}$ & $-35.73^{\#}$ & $<0.0001$ \\
PSQI & $-53.41^{\#}$ & $-29.46^{\#}$ & $-23.94^{*}$ & $<0.0001$ \\
SF-12 PCS & $-59.85^{\#}$ & $-44.45^{\# \#}$ & $-15.39^{\text {ns }}$ & $<0.0001$ \\
SF-12 MCS & $-41.97^{\#}$ & $-16.46^{\text {ns }}$ & $-25.51^{* *}$ & $<0.0001$ \\
\hline
\end{tabular}

Notes: $* P<0.05 ; * * P<0.01 ;{ }^{*} P<0.001$; ${ }^{\# P}<0.000$ I; ns not significant.

Abbreviations: BDI, Beck's Depression Inventory; BPI, Brief Pain Inventory; FM, fibromyalgia; LBP, low-back pain; MCS, mental component summary; PCS, physical component summary; PSQI, Pittsburgh Sleep Quality Index; SF-12, Short-Form Health Survey SF-12; vs, versus.

$(P<0.05$ in relation to low-back pain patients). Total depression scores were highest among patients with fibromyalgia and were significantly different from those of both the controls and of patients with low-back pain $(P<0.0001)$. Sleep quality was poor in fibromyalgia patients and in patients with low-back pain, although sleep quality was worse in fibromyalgia patients $(P<0.05)$. Physical health was also poor in both patient groups $(P<0.0001$ in relation to controls), whereas the mental health status was similar in the controls and in patients with low-back pain and was significantly lower in patients with fibromyalgia $(P<0.0001$ in relation to the controls and $P<0.01$ in relation to patients with low-back pain).
Suicidal ideation was almost completely absent among the controls, with only two (4\%) subjects reporting passive suicidal ideation; was low among patients with low-back pain, with six (18.8\%) patients reporting passive suicidal ideation; and was prominent among patients with fibromyalgia, with $18(41 \%)$ patients reporting passive suicidal ideation and six (13.6\%) patients reporting active suicidal ideation. The difference among the groups was highly significant $\left(\chi^{2}: 24.98 ; P<0.0001\right)$ (Figure 1).

The presence of the risk of suicide, as defined by the cutoff point on the Plutchik scale (6 points), was also higher among patients with fibromyalgia ( $\mathrm{N}=36$ [81.8\%]), which was in contrast with patients with low-back pain $(\mathrm{N}=10$ $[31.3 \%])$ and the controls $(\mathrm{N}=4[8 \%])\left(\chi^{2}: 52.99, P<0.0001\right)$ (Figure 1).

When the data relative to suicidal ideation and the risk of suicide were adjusted in relation to patient age and sex, the likelihood of suicidal ideation and the risk of suicide in patients with fibromyalgia compared with controls was significantly increased. Among patients with low-back pain, the likelihood of suicidal ideation and the risk of suicide, although statistically significant, was substantially lower. The odds ratios (ORs) for both pathologies are shown in Table 3.

In the predictive models, depression was the only factor associated both with suicidal ideation (OR 1.183, $95 \%$ confidence interval $[\mathrm{CI}] 1.068-1.311, P=0.001)$

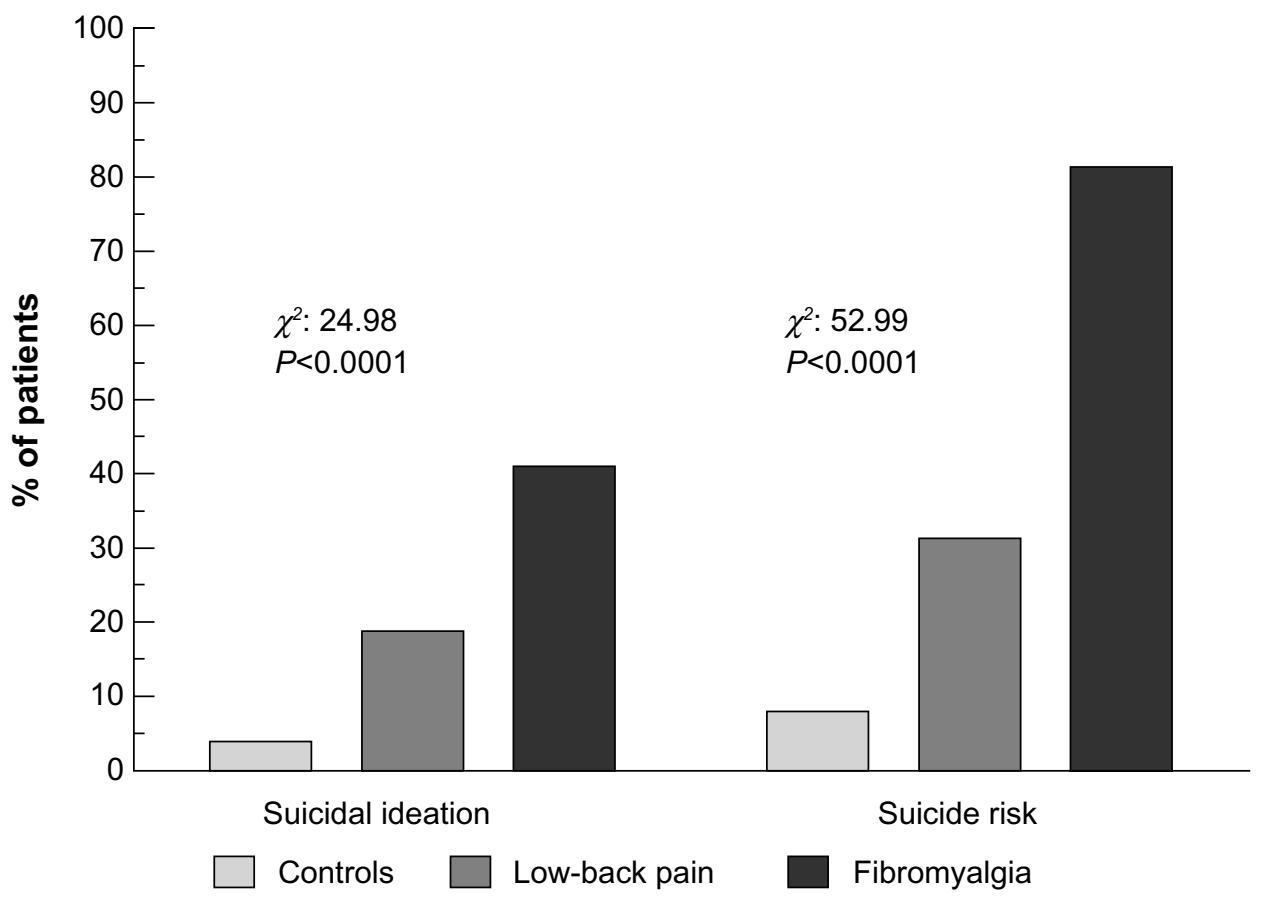

Figure I Suicidal ideation and risk of suicide in the studied groups. 
Table 3 ORs for suicidal ideation and for risk of suicide in both patient groups as compared with controls

\begin{tabular}{llll}
\hline & OR & $95 \% \mathbf{C l}$ & P-value \\
\hline $\begin{array}{llll}\text { Suicidal ideation } \\
\text { Fibromyalgia }\end{array}$ & 26.889 & $5.72-126.42$ & $<0.000$ I \\
$\begin{array}{l}\text { Low-back pain } \\
\text { Risk of suicide }\end{array}$ & 4.583 & $0.826-25.432$ & 0.082 \\
$\quad$ Fibromyalgia & 48.000 & $12.929-178.206$ & $<0.000$ I \\
Low-back pain & 4.725 & $1.297-17.209$ & 0.019 \\
\hline
\end{tabular}

Abbreviations: $\mathrm{Cl}$, confidence interval; $\mathrm{OR}$, odds ratio.

and the risk of suicide (OR 1.159, 95\% CI 1.046-1.283, $P=0.005)$.

\section{Discussion}

Our data show that both suicidal ideation and the risk of suicide were higher in both patient groups compared with the controls, but they were highest in patients with fibromyalgia. Depression was the factor most strongly associated with both suicidal ideation and the risk of suicide. Examining the characteristics of both patient groups, it was apparent that pain intensity and physical health were similar but that the severity of depression and mental health status were significantly worse among patients with fibromyalgia. Sleep quality was poor in both groups but was worse among patients with fibromyalgia.

From our results, it can be argued that fibromyalgia is not associated with an increased risk of suicidal ideation by itself but is only associated with concomitant depression. This observation agrees with the observations of Ratcliffe et $\mathrm{a}^{11}$ who found that fibromyalgia was positively associated with suicidal ideation and suicide attempts but that this association disappeared after adjusting the data for concomitant psychiatric comorbidity. Similar findings have also been recently reported by Ilgen et al. ${ }^{13}$ In a previous study, we found that patients with fibromyalgia who had previously attempted suicide had depression scores that were significantly higher than those who did not attempt suicide. ${ }^{3}$ Additionally, in a cross-sectional study evaluating the relationship between suicidal ideation and the symptoms of fibromyalgia, we found that among the symptoms that were related to suicidal ideation, depression showed the largest effect. ${ }^{28}$ However, it is important to remember that fibromyalgia and depression are strongly related. Patients with fibromyalgia frequently suffer from a comorbid major depressive disorder, and the relatives of patients with fibromyalgia have been shown to experience depression at a frequency rate that is almost equal to those of relatives that suffer from depression. ${ }^{29,30}$ The hypothesis that fibromyalgia affects affective spectrum disorders is widely accepted, and both pathologies have been shown to share common pathophysiological mechanisms. ${ }^{30,31}$ Thus, the risk of suicidal behaviors (either suicidal ideation or suicide attempts) must be seriously considered by the attending physician when dealing with patients diagnosed with fibromyalgia, even if they have not been previously diagnosed with a major depressive disorder by a psychiatrist.

Although the sample of patients with chronic low-back pain in our study was included as a chronic pain group for comparative purposes, interesting considerations can be made from these findings. Depression has been found to be frequent among patients suffering low-back pain. ${ }^{15,32}$ Ilgen et al ${ }^{14}$ found that back pain, together with migraines and psychogenic pain, was associated with an increased risk of death from suicide, a risk that persisted after adjusting the data for sociodemographic data and psychiatric comorbidity.

The main limitation of our study is the limited sample size, which was large enough to fulfill the first objective of our study but not large enough to adequately accomplish the second objective. A larger sample size would most likely be able to discriminate the relative weight of sleep disturbances and pain intensity in predicting suicidal ideation and the risk of suicide. An additional limitation is that the control group was significantly different from both patient groups; the controls had better education and employment statuses. Although we do not believe that this fact greatly influenced the results of this study, it is a selection bias that must be acknowledged. Additionally, we did not evaluate other factors that may have influenced our results, such as a family history of suicide, the existence of previous suicide attempts, and the duration of the disease. The first two factors are well known general factors for the predisposition of suicide, ${ }^{8}$ whereas the last factor is pain-specific and has a relationship with suicidal behaviors that has not been thoroughly investigated. However, there is some evidence that suicidal ideation is more probable among patients with long-lasting pain than among those with recent-onset pain. ${ }^{5}$ Additionally, this study was an exploratory study that aimed to evaluate suicidal ideation and risk in patients with fibromyalgia compared with healthy subjects and patients with low-back pain. As it was not possible to evaluate every factor that is potentially related to suicidal behaviors because of the limited sample size, we focused our attention on the factors thought to be most relevant to suicidal behaviors in chronic-pain patients, such as pain intensity, sleep disturbances, and mental health status.

Despite these limitations, we believe that our study provides relevant data that can be added to the growing body 
of evidence that links fibromyalgia with an increased risk of suicidal behaviors. This increased risk is mainly explained by the presence of depressive symptoms, highlighting the importance of adequately evaluating and treating the symptoms of depression.

\section{Disclosure}

The authors report no conflicts of interest in this work.

\section{References}

1. Dreyer L, Kendall S, Daneskiøld-Samsoe B, Bartels EM, Bliddal H. Mortality in a cohort of Danish patients with fibromyalgia: increased frequency of suicide. Arthritis Rheum. 2010;62(10):3101-3108.

2. Wolfe F, Hassett AL, Walitt B, Michaud K. Mortality in fibromyalgia: a study of 8,186 patients over thirty five years. Arthritis Care Res. 2011;63(1):94-101.

3. Calandre EP, Vilchez JS, Molina-Barea R, et al. Suicide attempts and risk of suicide in patients with fibromyalgia: a survey in Spanish patients. Rheumatology. 2011;50(10):1889-1893.

4. Fishbain DA. The association between chronic pain and suicide. Semin Clin Neuropsychiatry. 1999;4(3):221-227.

5. Tang NKY, Crane C. Suicidality in chronic pain: a review of the prevalence, risk factors and psychological links. Psychol Med. 2006;36(5): 575-586.

6. Moldofsky H. The significance, assessment, and management of nonrestorative sleep in fibromyalgia syndrome. CNS Spectrums. 2008; 13(5):22-26.

7. Arnold LM, Claw DJ, McCarberg BH. Improving the recognition and diagnosis of fibromyalgia. Mayo Clin Proc. 2011;86(5):456-464.

8. Nock MK, Borges G, Bromet EJ, et al. Cross-national prevalence and risk factors for suicidal ideation, plans and attempts. Br J Psychiatry. 2008;192(2):98-105.

9. Pigeon WR, Pinquart M, Conner K. Meta-analysis of sleep disturbance and suicidal thoughts and behaviors. J Clin Psychiatry. 2012;73(9): e1160-e1167.

10. Queiroz LP. Worldwide epidemiology of fibromyalgia. Curr Pain Headache Rep. 2013;17(8):356.

11. Ratcliffe GE, Enns MW, Belik SL, Sareen J. Chronic pain conditions and suicidal ideation and suicidal attempts: an epidemiological perspective. Clin J Pain. 2008;24(3):204-210.

12. Braden JB, Sullivan MD. Suicidal thoughts and behavior among adults with self-reported pain conditions in the national comorbidity survey replication. J Pain. 2008;9(12):1106-1115.

13. Ilgen MA, Zivin K, McCammon RJ, Valenstein M. Pain and suicidal thoughts, plans and attempts in the United States. Gen Hosp Psychiatry. 2008;30(6):521-527.

14. Ilgen MA, Kleinberg F, Ignacio RV, et al. Noncancer pain conditions and risk of suicide. JAMA Psychiatry. 2013;70(7):692-697.

15. Sullivan MJL, Reesor K, Mikail S, Fisher R. The treatment of depression in chronic low back pain: review and recommendations. Pain. 1992;50(1):5-13.
16. Rush AJ, Polatin P, Gatchel RJ. Depression and chronic low back pain. Spine. 2000;25(20):2566-2571.

17. Marty M, Rozenberg S, Duplan B, Thomas P, Duquesnoy B, Allaert F. Quality of sleep in patients with chronic low back pain: a case-control study. Eur Spine J. 2008;17(6):839-844.

18. Bahouq H, Allali F, Rkain H, Hmamouchi I, Hajjaj-Hassouni N. Prevalence and severity of insomnia in chronic low back pain patients. Rheumatol Int. 2013;33(5):1277-1281.

19. Wolfe F, Smythe HA, Yunus MB, et al. The American College of Rheumatology 1990 criteria for the classification of fibromyalgia: report of the multicenter criteria committee. Arthritis Rheum. 1990;33(2): $160-172$.

20. Smith MT, Perlis ML, Haythornthwaite JA. Suicidal ideation in outpatients with chronic musculoskeletal pain: an exploratory study of the role of sleep onset insomnia and pain intensity. Clin J Pain. 2004; 20(2):111-118.

21. Smith MT, Edwards RR, Robinson RC, Dworkin RH. Suicidal ideation, plans, and attempts in chronic pain patients: factors associated with increased risk. Pain. 2004;111(1-2):201-208.

22. Kanzler KE, Bryan CG, McGeary DD, Morrow CE. Suicidal ideation and perceived burdensomeness in patients with chronic pain. Pain Pract. 2012;12(8):602-609.

23. Vazquez C, Sanz J. Fiabilidad y valores normales de la versión española del inventario para la depresión de Beck de 1978. Clín Salud. 1997;8(3):403-422.

24. Rubio G, Montero I, Jaúregui J, et al. Validación de la escala de riesgo de suicidio de Plutchik en la población española. Arch Neurobiol. 1998;61(2):143-152.

25. Royuela A, Macías JA. Propiedades clinimétricas de la versión castellana del cuestionario de Pittsburgh. Vigilia-Sueño. 1998;9(2): 81-94.

26. Badia X, Muriel C, Gracia A, et al. Validación española del cuestionario Brief Pain Inventory en pacientes con dolor de causa neoplásica. Med Clin (Barc). 2003;120(2):52-59.

27. Vilagut G, Valderas JM, Ferrer M, Garin O, López-García E, Alonso J. Interpretación de los cuestionarios de salud SF-36 y SF-12 en España: componente físico y mental. Med Clin (Barc). 2008;130(2):726-735.

28. Calandre EP, Navajas-Rojas MA, Ballesteros J, Garcia-Carrillo J, Garcia-Leiva JM, Rico-Villademoros F. Suicidal ideation in patients with fibromyalgia: a cross-sectional study. Pain Pract. Epub January 17, 2014.

29. Raphael KG, Janal MN, Nayak S, Schwartz JE, Gallagher RM. Familial aggregation of depression in fibromyalgia: a community-based test of alternate hipotheses. Pain. 2004;110(1-2):449-460.

30. Pae CU, Luyten P, Marks DM, et al. The relationship between fibromyalgia and major depressive disorder: a comprehensive review. $\mathrm{Cur} \mathrm{Med}$ Res Opin. 2008;24(8):2359-2371.

31. Gracely RH, Ceko M, Bushnell MC. Fibromyalgia and depression. Pain Res Treat. 2012;2012:486590.

32. Bener A, Verjee M, Dafeeah EE, et al. Psychological factors: anxiety, depression, and somatization symptoms in low back pain patients. J Pain Res. 2013;(6):95-101.
Neuropsychiatric Disease and Treatment

\section{Publish your work in this journal}

Neuropsychiatric Disease and Treatment is an international, peerreviewed journal of clinical therapeutics and pharmacology focusing on concise rapid reporting of clinical or pre-clinical studies on a range of neuropsychiatric and neurological disorders. This journal is indexed on PubMed Central, the 'PsycINFO' database and CAS.

\section{Dovepress}

The manuscript management system is completely online and includes a very quick and fair peer-review system, which is all easy to use. Visit http://www.dovepress.com/testimonials.php to read real quotes from published authors. 